SCIENTIFIC REPORT

\title{
Outcomes of referrals by community optometrists to a hospital glaucoma service
}

\author{
B Bowling, S D M Chen, J F Salmon
}

Br J Ophthalmol 2005;89:1 102-1 104. doi: 10.1136/bjo.2004.064378

Aim: To determine the outcomes resulting from optometric referrals to a specialist glaucoma screening clinic over a 10 year period.

Methods: Details of the initial clinical assessment of all new patients referred to the adult glaucoma screening clinic at Oxford Eye Hospital were collected prospectively from July 1994 to June 2004.

Results: Optometrists working in community practice initiated 2505 referrals. Of these, glaucoma was confirmed in 510 patients $(20.4 \%)$, including 160 with normal intraocular pressure (IOP). A diagnosis of ocular hypertension was made in 747 patients $(29.8 \%$ of referrals) and $125(5.0 \%)$ were categorised as glaucoma suspects. There was no evidence of a diagnostic trend over the period of data collection. Treatment to lower IOP was commenced in 458 patients (18.3\%). Nearly half of those referred, 1148 (45.8\%), were discharged from ophthalmological review at the first visit.

Conclusion: In this survey, the largest of its nature, only one in five subjects had glaucoma and nearly half were discharged from hospital ophthalmological review. The findings provide a baseline against which the effectiveness of any future system of glaucoma detection in the United Kingdom can be compared.

$P$ artly in response to the increasing burden on the hospital eye service resulting from demographic changes, major modifications to the way glaucoma detection and care are carried out in the United Kingdom are likely in the near future. Government plans envisage a significant proportion of clinical glaucoma management being transferred from hospital to primary care. ${ }^{1}$ Central to the new system will be the development of a cadre of specialist optometrists, who, it is proposed, will assume much of the work of screening and initial management of referrals for suspected glaucoma currently carried out by ophthalmologists.

In light of these impending developments in service provision, we examined the outcomes of glaucoma referrals to our unit under the current system. Our principal aim was the provision of feedback to local referral sources, comparing our own data with previously published results. Given the large number of referrals surveyed, the information furnished should also be of interest to a geographically and professionally wider audience, aiding planning and resource allocation and providing a baseline against which the effectiveness of any novel system can be compared.

\section{METHODS}

During the 10 year period from July 1994 to June 2004, a standardised proforma was used to collect data relating to the first assessment of every new referral for suspected glaucoma to the adult glaucoma screening clinic at the Oxford Eye
Hospital, Oxford, United Kingdom. Although details of the examining ophthalmologist in each case were not collected, most of the patients were seen by the same glaucoma specialist (JFS), with a small proportion assessed by a glaucoma fellow. The data do not include referrals to other consultants at the same hospital during this period.

Information recorded on the proforma included source of referral, patient age, Afro-Caribbean ethnicity, and intraocular pressure (IOP) at the first hospital assessment; a subjective assessment of whether the optic disc appearances were distinctly glaucomatous (unequivocal focal, or concentric neuroretinal rim loss and/or greater than 0.2 difference in cup:disc ratio between two eyes with symmetrical disc diameters), distinctly non-glaucomatous (including characteristic of other pathology) or of uncertain status; a subjective assessment of the visual fields as characteristically glaucomatous (deep paracentral, arcuate, ring, nasal step, or end stage defect) non-glaucomatous (including characteristic of other pathology, particularly central neurological disease) or uncertain; and the presence on examination of other ocular pathology. A provisional diagnosis was determined based only on information available at the initial assessment:

(1) glaucoma: IOP $>21 \mathrm{~mm} \mathrm{Hg}$ with characteristic optic disc and/or visual field changes

(2) normal tension glaucoma (NTG): as glaucoma but IOP $\leqslant 21 \mathrm{~mm} \mathrm{Hg}$ at the initial hospital visit

(3) glaucoma suspect: irrespective of IOP, not possible with reasonable certainty to categorise the appearance of the optic discs and visual fields of either eye as clearly glaucomatous, but unable to classify those of both eyes as clearly non-glaucomatous

(4) ocular hypertension (OHT): defined as IOP $>21 \mathrm{~mm} \mathrm{Hg}$ without glaucomatous optic disc or visual field changes

(5) no glaucoma or OHT.

A diagnosis of other visual pathway pathology was recorded in addition to (1)-(5) as appropriate.

A record was made of whether the patient was discharged from ophthalmological review and whether IOP lowering treatment was instituted.

\section{RESULTS}

A total of 2620 new referrals were received from community primary care sources, of which 2505 were initiated by optometric practices. Referrals initiated by a general practitioner without optometric input were excluded from the analysis. The average age of the patients was 63 years (SD 13.2 , range $19-94)$. Only 26 patients (1.0\%) were of AfroCaribbean ethnic background.

Abbreviations: IOP, intraocular pressure; NTG, normal tension glaucoma; OHT, ocular hypertension 


\begin{tabular}{|c|c|c|c|c|}
\hline Year & $\begin{array}{l}\text { No of } \\
\text { referrals }\end{array}$ & $\begin{array}{l}\text { Glaucoma } \\
\text { including NTG } \\
\text { (\%) }\end{array}$ & $\begin{array}{l}\text { Glaucoma } \\
\text { suspect (\%) }\end{array}$ & OHT (\%) \\
\hline 1994 & 133 & $27(20)$ & 11 (8) & $26(20)$ \\
\hline 1995 & 244 & 39 (16) & $19(8)$ & 70 (29) \\
\hline 1996 & 210 & $52(25)$ & $17(8)$ & 71 (34) \\
\hline 1997 & 194 & $48(25)$ & $8(4)$ & 66 (34) \\
\hline 1998 & 252 & $58(23)$ & $12(5)$ & $70(28)$ \\
\hline 1999 & 229 & $46(20)$ & $5(2)$ & $110(48)$ \\
\hline 2000 & 256 & $55(21)$ & $11(4)$ & $91(36)$ \\
\hline 2001 & 235 & $50(21)$ & $6(3)$ & $69(29)$ \\
\hline 2002 & 274 & 53 (19) & $11(4)$ & 65 (24) \\
\hline 2003 & 278 & 46 (17) & $12(4)$ & 63 (23) \\
\hline 2004 & 200 & 36 (18) & $13(7)$ & $46(23)$ \\
\hline
\end{tabular}

\section{Diagnostic outcomes}

In all, 510 patients $(20.4 \%$, 99\% confidence interval (CI) $18.3 \%$ to $22.5 \%$ ) had chronic glaucoma, and of these 160 (31.4\% of glaucomas; $6.4 \%$ of referrals, $99 \%$ CI $5.1 \%$ to $7.7 \%$ ) fell within the NTG diagnostic category as defined above. Significant additional visual pathway pathology was present in nine $(1.8 \%)$ of the patients with glaucoma. OHT was found in 747 patients $(29.8 \%, 99 \%$ CI $27.4 \%$ to $32.2 \%)$, of whom 27 (3.6\% of patients with OHT, $1.1 \%$ of referrals) had significant additional pathology; 125 of the referred patients $(5.0 \%, 99 \%$ CI $3.9 \%$ to $6.1 \%$ ) were classified as "glaucoma suspects." Seven $(5.6 \%)$ of the glaucoma suspects had additional ocular or other visual pathway pathology; 1123 (44.8\%, 99\% CI $42.2 \%$ to $47.4 \%$ ) of referrals were judged to have no evidence of glaucoma or OHT. Of this group, 149 (13.3\%, equating to $5.9 \%$ of referrals) had other pathology. The results, divided on a yearly basis over 10 years, are summarised in table 1 .

\section{Management outcomes}

A total of 1148 patients $(45.8 \%$ of optometrist initiated referrals, $99 \%$ CI $43.2 \%$ to $48.4 \%$ ) were discharged from ophthalmological review; 942 (82.1\% of discharged patients) had no evidence of glaucoma or OHT, though 78 of these (6.8\% of discharges) had other significant ocular or other visual pathway pathology. Two hundred and one discharged patients $(17.5 \%)$ had OHT, the majority of whom had a highest IOP of $22 \mathrm{~mm} \mathrm{Hg}$ or $23 \mathrm{~mm} \mathrm{Hg}$. Four patients with glaucoma $(0.3 \%$ of discharged patients, $0.8 \%$ of those with confirmed glaucoma), including three with NTG, were discharged, as was one glaucoma suspect. IOP lowering treatment (including laser and surgery) was instituted for 458 patients in total $(18.3 \%$ of referrals, $99 \%$ CI $16.3 \%$ to $20.3 \%$ ). Of these, $363(79.3 \%)$ had glaucoma (including 87 patients with NTG, $19.0 \%$ of those treated), 75 (16.4\% of those treated) had OHT, and 20 (4.4\%) were glaucoma suspects.

\section{DISCUSSION}

The outcomes of patients referred to an ophthalmologist for suspected glaucoma have been examined in previous studies. ${ }^{2-13}$ The results of these are set out in table 2 .

Differences between surveys are evident across a range of parameters including diagnostic definitions and classification systems, methods of data collection, referral sources and population demographics. Some studies included only a small number of patients, and have been criticised for the resultant limited statistical legitimacy. ${ }^{14}$ It is important to emphasise in this context that our own reported diagnostic outcomes are based exclusively on the information available at the initial consultation. This should also be borne in mind when considering our figures for the initiation of treatment.

Table 2 Previous studies of the outcome of optometric referrals for suspected glaucoma

\begin{tabular}{|c|c|c|c|c|c|c|}
\hline Authors & $\begin{array}{l}\text { Year of } \\
\text { publication }\end{array}$ & $\begin{array}{l}\text { Sample } \\
\text { size }\end{array}$ & $\begin{array}{l}\text { Confirmed glaucoma } \\
(\%)\end{array}$ & $\begin{array}{l}\text { Glaucoma suspect } \\
(\%)\end{array}$ & ОНт (\%) & $\begin{array}{l}\text { No glaucoma, } \\
\text { no OHT } \\
(\%)\end{array}$ \\
\hline Clearkin and Harcourt & 1983 & 34 & $11(32)$ & $2(6)$ & $2(6)$ & $19(56)$ \\
\hline Harrison et al & 1988 & $147^{*}$ & $33(22)$ & $73(50) \dagger$ & & $41(28)$ \\
\hline Brittain et al & 1988 & 93 & $41(44)$ & $20(22)$ & NA & $32(34)$ \\
\hline Tuck and Crick & 1991 & 704 & $283(40)$ & $222(32) \dagger$ & & $199(28)$ \\
\hline Sheldrick et al & 1994 & 213 & $68(32)$ & NA & $48(23)$ & $97(46)$ \\
\hline Bell and O'Brien & 1997 & $271 \neq$ & $46(17)$ & $13(5)$ & $113(42)$ & $112(41)$ \\
\hline Vernon (1988 group) & 1998 & $75^{+}$ & $36(48)$ & 9 (12) & $27(36)$ & $3(4)$ \\
\hline Vernon (1993 group) & 1998 & 71 & $24(34)$ & $11(15)$ & $16(23)$ & $20(28)$ \\
\hline Newman et al & 1998 & 82 & $35(43)$ & $1(1)$ & $16(20)$ & $30(37)$ \\
\hline Theodossiades and Murdoch & 1999 & 87 & $19(22)$ & $18(21)$ & $12(14)$ & $38(44)$ \\
\hline Pooley and Frost & 1999 & 19 & $5(26)$ & NA & NA & NA \\
\hline Vernon and Ghosh (control group) & 2001 & 105 & 39 (37) & $9(9)$ & $17(16)$ & 40 (38) \\
\hline $\begin{array}{l}\text { Vernon and Ghosh (intervention } \\
\text { group) }\end{array}$ & 2001 & 102 & 32 (31) & $7(7)$ & 19 (19) & $44(43)$ \\
\hline Theodossiades et al (control group) & 2004 & 119 & $55(46) \dagger$ & & NA & NA \\
\hline $\begin{array}{l}\text { Theodossiades et al (intervention } \\
\text { group) }\end{array}$ & 2004 & 210 & $102(49) \dagger$ & & NA & NA \\
\hline Bowling et al & 2005 & 2506 & $511(20)$ & $125(5)$ & $747(30)$ & $1123(45)$ \\
\hline
\end{tabular}

*Includes 27 direct GP referrals.

†Figures published in combined diagnostic categories.

flncludes 11 direct GP referrals.

NA, not available. 
Our confirmed glaucoma rate of just over $20 \%$ is similar to the $17 \%$ rate found in the Edinburgh study of 271 patients seen over 6 months from 1993 to $1994^{7}$ and the $22 \%$ found by Harrison et $a l^{3}$ and Theodossiades and Murdoch. ${ }^{10}$ The diagnosis of NTG is complicated by considerations such as diurnal IOP variation. ${ }^{15}$ Theodossiades and colleagues ${ }^{10}$ specifically excluded NTG as a category distinct from open angle glaucoma in their study of referrals as it was thought that the diagnosis could not be made authoritatively following a single clinic appointment. Based on the IOP at the initial hospital examination, approximately one third $(31 \%)$ of our confirmed glaucomas fell within the NTG group, a similar rate to the $33 \%$ reported by the Edinburgh study. ${ }^{7}$

Our OHT rate was just under $30 \%$. There has been substantial variation in reported rates, which in recent studies range from $14 \%$ to $42 \%{ }^{7}{ }^{10}$ Not all published studies have included OHT as a distinct diagnostic category, including the largest before our own, ${ }^{5}$ which grouped patients with OHT and glaucoma suspects together in the category "uncertain, follow up required." We found a glaucoma suspect rate of $5.0 \%$. Half of the studies reviewed did not have an explicit "glaucoma suspect" grouping, and valid comparison with other published data is particularly difficult with respect to this category, which, almost by definition, may be prone to a higher degree of subjectivity.

Treatment to reduce IOP was instituted for 458 patients (18.3\% of referrals), mainly for glaucoma. A minority of those treated had OHT or were glaucoma suspects. While some previous surveys detail the proportion of patients with OHT commenced on treatment, none has reported the number of treated confirmed glaucoma patients. Some of our patients are likely to have been treated subsequent to the first consultation upon which the presented findings are based. This may apply particularly to patients with NTG, for whom treatment is often withheld pending evidence of progression; in our survey, $79 \%(276 / 350)$ of those with glaucoma featuring elevated IOP were treated at the first visit, but only $54 \%(87 / 160)$ of those with NTG.

A total of $1148(45.8 \%)$ patients were discharged from ophthalmological review, the majority of whom had no evidence of glaucoma; some had OHT but were considered to be at extremely low risk of developing glaucoma, and others had pathology which did not require further ophthalmological intervention at the time of assessment. Four patients with glaucoma (including three with NTG) and one glaucoma suspect were discharged, as their life expectancy was considered low in comparison with the risk of visually significant glaucomatous progression. In the only other study reporting a specific figure for patients who were discharged, $30 \%$ required no follow up. ${ }^{7}$ By no means will every referral have been made in the belief that the patient definitely had glaucoma. This has been studied by Tuck, ${ }^{16}$ who found that $74 \%$ of the patients referred by an optometrist with "almost definite" glaucoma were confirmed as having the condition, compared with only $21 \%$ of "possible" glaucomas. Community optometrists are under considerable pressure to detect every case of sight threatening disease, ${ }^{17}$ with a missed diagnosis having potentially serious ramifications for the responsible practitioner. In contrast, little disadvantage results from a false positive referral. Many patients will have been referred in the belief that they had OHT rather than glaucoma and that only monitoring was required. Under the present system there may be no alternative in these circumstances to a request for appraisal by the hospital eye service, but these patients may in the future be managed in the community by a specialist optometrist. Henson et al have reported a cost effective $40 \%$ reduction in new glaucoma referrals to Manchester Royal Eye Hospital from a scheme involving initial assessment by specially trained community optometrists, ${ }^{18}$ although figures for diagnostic accuracy have not yet been published.

In conclusion, this study is the largest survey to determine the outcomes resulting from optometric referrals for suspected glaucoma to a specialist hospital eye clinic. It is hoped that planned changes to the system of referral for suspected glaucoma in the United Kingdom will lead to a substantial decrease in the number of false positives reaching the hospital eye service, without a commensurate increase in false negatives. ${ }^{1}$

\section{ACKNOWLEDGEMENTS}

The authors are grateful to Peter McKenzie for help with the collation of the data, and to Nicola Alder for statistical advice.

\section{Authors' affiliations}

B Bowling, S D M Chen, J F Salmon, Oxford Eye Hospital, Radcliffe Infirmary, Woodstock Road, Oxford, OX2 6HE, UK

Competing interests: none declared

Correspondence to: J F Salmon, MD, FRCOphth, Oxford Eye Hospital, Radcliffe Infirmary, Woodstock Road, Oxford, OX2 6HE, UK; john. salmon@orh.nhs.uk

Accepted for publication 17 March 2005

\section{REFERENCES}

1 Glaucoma Subgroup Report. In: First report of the National Eye Care Services Steering Group, National Eye Care Steering Group. London: Department of Health, 2004:1-13.

2 Clearkin L, Harcourt B. Referral pattern of true and suspected glaucoma to an adult ophthalmic clinic. Trans Ophthalmol Soc UK 1983;103:284-7.

3 Harrison RJ, Wild JM, Hobley AJ. Referral patterns to an ophthalmic outpatient clinic by general practitioners and ophthalmic opticians and the role of these professionals in screening for ocular disease. BMJ 1988;297:1 162-7.

4 Brittain GPH, Austin DJ, Kelly SP. A prospective study to determine sources and diagnostic accuracy of glaucoma referrals. Health Trends 1988;20:43-4.

5 Tuck MW, Crick RP. Efficiency of referral for suspected glaucoma. BMJ 1991;302:998-1000.

6 Sheldrick JH, $\mathrm{Ng} \mathrm{C}$, Austin DJ, et al. An analysis of referral routes and diagnostic accuracy in cases of suspected glaucoma. Ophthalmic Epidemiol 1994;1:31-9.

7 Bell RWD, O'Brien C. The diagnostic outcome of new glaucoma referrals. Ophthalmic Physiol Opt 1997; 17:3-6.

8 Vernon SA. The changing pattern of glaucoma referrals by optometrists. Eye $1998 ; 12: 854-7$.

9 Newman DK, Anwar S, Jordan K. Glaucoma screening by optometrists: positive predictive value of visual field testing. Eye 1998;12:921-4.

10 Theodossiades J, Murdoch I. Positive predictive value of optometrist-initiated referrals for glaucoma. Ophthalmic Physiol Opt 1999;19:62-7.

11 Pooley JE, Frost EC. Optometrists' referrals to the hospital eye service. Ophthalmic Physiol Opt 1999;19:16-24.

12 Vernon SA, Ghosh G. Do locally agreed guidelines for optometrists concerning the referral of glaucoma suspects influence referral practice? Eye $2001 ; 15: 458-63$

13 Theodossiades J, Murdoch I, Cousens S. Glaucoma case finding: a clusterrandomised intervention trial. Eye 2004; 18:483-90.

14 Gilchrist J. Accuracy of glaucoma referrals: need to report precision of estimates. Br J Ophthalmol 2000;84:124.

15 Ido T, Tomita G, Kitazawa Y. Diurnal variation of intraocular pressure of normal-tension glaucoma. Ophthalmology 1991;98:296-300.

16 Tuck MW. Referrals for suspected glaucoma: an International Glaucoma Association survey. Ophthalmic Physiol Opt 1991;11:22-6.

17 Stevenson R. Automated perimetry by optometrists in patients at low risk of glaucoma [comment]. Br J Ophthalmol 1999;83:759-60.

18 Henson DB, Spencer AF, Harper R, et al. Community refinement of glaucoma referrals. Eye 2003;17:21-6. 